\title{
A Combination of Findings Obtained from Pre- and Postoperative Imaging Predict Recovery of Urinary Continence After Non-nerve-sparing Laparoscopic Radical Prostatectomy
}

\author{
TAKEHISA ONISHI, SHO SEKITO, TAKESHI TERABE and TAKUJI SHIBAHARA \\ Department of Urology, Ise Red Cross Hospital, Ise, Japan
}

\begin{abstract}
Background/Aim: The aim of the study was to identify the reliable predictor for early recovery of urinary continence (UC) after non-nerve-sparing laparoscopic radical prostatectomy (NNS-LRP) according to the findings of pre- and postoperative imaging. Materials and Methods: A retrospective analysis of 215 patients who underwent NNS-LRP was carried out. Early recovery of UC was defined as using no pads or one security pad per day within 3 months. Preoperative membranous urethral length (MUL) measured on MRI and postoperative bladder neck angle (BNA) identified by cystography were analyzed to evaluate the relationship with recovery of UC. Patients were divided into three groups based on MUL and BNA (Group A: $M U L \geq 12.1 \mathrm{~mm}$ and $B N A \geq 103^{\circ}$, Group B: either $M U L \geq 12.1 \mathrm{~mm}$ or $B N A \geq 103^{\circ}$, Group $C$ : $M U L<12.1 \mathrm{~mm}$ and $B N A<103^{\circ}$. Results: Early recovery rates were $80.3 \%$ in patients with $M U L \geq 12.1 \mathrm{~mm}, 37.5 \%$ in patients with $M L U<12.1(p<0.001)$, and $77.8 \%$ in patients with $B N A$ $\geq 103^{\circ}, 50 \%$ in patients with $B N A<103^{\circ}(p<0.001)$. In the combination of the two parameters, early recovery rates were $90.4 \%, 58 \%$, and $36.1 \%$ in group $A, B$ and $C$ respectively $(p<0.001)$. Kaplan-Meier curve of the time to recovery of $U C$ showed significant differences among the three groups (log rank test: $p<0.001)$. Conclusion: A combination of preoperative MUL and postoperative BNA was the reliable predictor of recovery of UC after NNS-LRP. Longer MUL with wider BNA is significantly and positively associated with an early recovery of $U C$.
\end{abstract}

Radical prostatectomy (RP) is a standard treatment option for patients with localized prostate cancer. Despite the advancements of pelvic anatomy and refinement of surgical

Correspondence to Takehisa Onishi, MD, 471-2 Hunae, Ise, Mie, 516-8512, Japan. Tel: +81 596282171, Fax: +81 596282965, e-mail: takehisa@ise.jrc.or.jp

Key Words: Prostate cancer, laparoscopic surgery, radical prostatectomy, urinary incontinence. techniques, the incidence of urinary incontinence (UI) remains relatively high especially during the early period after RP. Postoperative UI is one of the most significant and disappointing adverse events with the potential for a negative impact on quality of life and represents a cause of anxiety for both patients and urologists $(1,2)$. Regardless of the type of surgical approach, the risk of postoperative UI after RP is influenced by various factors. Previous studies have reported several factors associated with postoperative UI: i) demographic factors, including age, prostate volume, prostatic apical shape, membranous urethral length and preoperative lower urinary tract symptoms (LUTS) (3-8), ii) surgical technique-related factors, including posterior and anterior wall reconstruction, nerve sparing procedure, and bladder neck preservation, which are potentially related to the early recovery of postoperative urinary continence (UC) (9-11). In addition to preoperative and intraoperative factors, postoperative findings, such as cystography suggested to be a reliable tool for predicting postoperative UI (12-16).

The aim of the present study was to pursue a reliable and convenient predictor obtained from pre- and postoperative imaging for early recovery of postoperative urinary continence (UC) after non-nerve-sparing laparoscopic radical prostatectomy (NNS-LRP) according to the findings of preand post-operative examinations in clinical practice.

\section{Patients and Methods}

A total of 223 patients who underwent NNS-LRP for clinically localized prostate cancer by a single surgeon (T.O) from April 2013 to May 2017 were evaluated.

The surgical procedure was as follows: The Retzius space was approached extraperitoneally and an antegrade prostatectomy was performed. After removal of prostate, we routinely performed double-layered posterior reconstruction of the rabdomyosphincter (the first layer is the fibrous tissue just beneath the urethra with the Denonvillier's fascia located halfway between the bladder and urethra, and the second layer is the bladder muscle and the fibrous tissue just below the urethra) and anterior reconstruction with urethral suspension (the stich was passed between the urethra and dorsal vein complex and then through the periosteum on the pubic 
bone). Vesicourethral anastomosis was performed as previously described by van Velthoven et al. (17).

All patients underwent preoperative magnetic resonance images (MRI) of the prostate for staging of the disease, and routine postoperative cystography 6 days after surgery to evaluate the leakage of the vesicourethral anastomosis site at the time of removal of urethral catheter. No patients had a history of UI before surgery. Among the 223 patients, 6 patients who had leakage during cystography with delay of catheter removal and 2 patients who lost postoperative follow-up were excluded from the analysis. Finally, 215 patients were evaluated. Study data were prospectively collected and retrospectively analyzed.

The patient's continence status was assessed by the patientreported pad usage over $24 \mathrm{~h}$ monthly after surgery until patients get continence recovery. Early recovery of UC was defined as using no pads or one security pad per day within 3 months. MRI was performed using a $1.5 \mathrm{~T}$ whole-body magnetic resonance scanner. The preoperative length of membranous urethral (MUL) was defined as a distance from apex of prostate to the urethra at the level of the penile bulb measured via T2-weighted sagittal and coronal MRI as previously reported $(5,18)$. Cystography was carried out routinely six days after surgery. A total of $200 \mathrm{ml}$ of saline solution containing contrast medium was infused into the bladder by gravity, followed by clamping of the Foley catheter. With the catheter under no tension, plain cystogram films were obtained in the anterior position view. The postoperative bladder neck angle (BNA) and the bladder neck position (BNP) was determined by the cystography. BNA was measured as the angle of the bladder neck to the bilateral bladder margin over the pelvic inlet (13) (Figure 1A). BNP was determined by the relative position of bladder neck to the pubic symphysis, and patients were divided into two groups according to the BNP; bladder neck position above the middle of the pubic symphysis (BNP-A) or below the middle of the pubic symphysis (BNP-B) (Figure 1B and C). MUL, BNA and BNP were retrospectively analyzed by two urologists who were blinded to the clinical results.

Ethical approval. All procedures performed in studies involving human participants were in accordance with the ethical standards of the institutional and/or national research committee and with the 1964 Helsinki declaration and its later amendments or comparable ethical standards. For this type of study formal consent was not required.

Statistical analyses. Statistical analyses were performed with EZR (Saitama Medical Center, Jichi Medical University, Saitama, Japan), which is a graphical user interface for R (The R Foundation for statistical Computing, Vienna, Austria). More precisely, it is a modified version of $\mathrm{R}$ commander designed to add statistical functions frequently used in biostatics (19). Differences between groups of patients in medians for quantitative variables and differences in distributions for categorical variables were tested with two tailed student $t$ test and Fisher exact tests, respectively. To determine the significant factors in predicting early recovery of UC, multivariate logistic regression analysis was carried out. Only the variables found to be significant on univariate analysis $(p<0.05)$ were entered into the multivariate analysis. Cut-off values for preoperative MUL and postoperative BNA were determined using receiver operating characteristics (ROC) analysis. The continence recovery rates were estimated by Kaplan-Meier methods and the
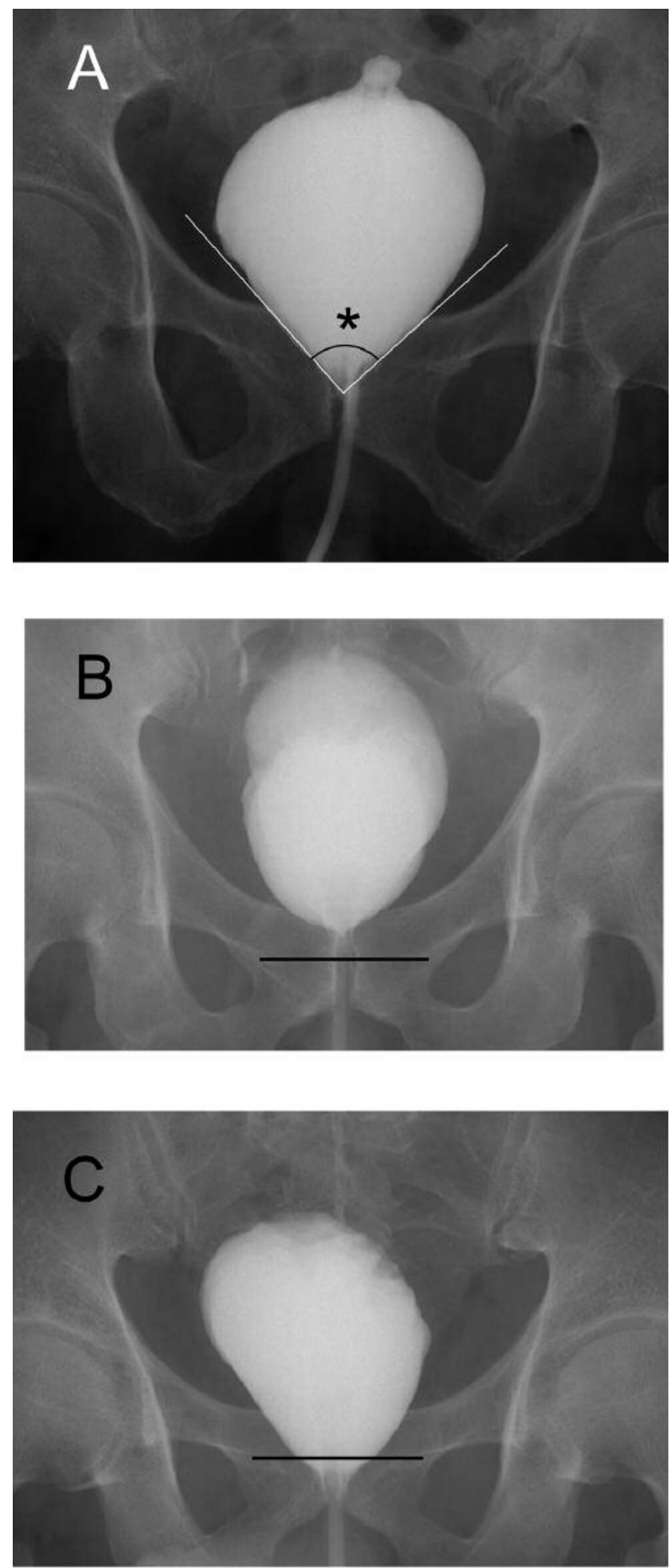

Figure 1. Parameters of cystography. A. The bladder neck angle was defined as the angle of the bladder neck to the bilateral bladder margin over the pelvic inlet (*). Patients were divided into two groups by postoperative cystogram according to the relative position of bladder neck (BNP) to the pubic symphysis. B. BNP above the middle of the pubic symphysis. C. BNP below the middle of the pubic symphysis. 
Table I. Patient characteristics.

\begin{tabular}{|c|c|c|c|c|}
\hline & \multirow[b]{2}{*}{ Total } & \multicolumn{2}{|c|}{ At 3 months after surgery } & \multirow[t]{2}{*}{$p$-Value } \\
\hline & & Continence $(+)$ & Continence (-) & \\
\hline Number of patients & 215 & 135 & 80 & \\
\hline \multicolumn{5}{|l|}{ Age at surgery, years } \\
\hline$(\operatorname{mean} \pm \mathrm{SD})$ & $67.5 \pm 5.7$ & $67.3 \pm 5.5$ & $68 \pm 5.9$ & 0.34 \\
\hline $\mathrm{BMI}(\operatorname{mean} \pm \mathrm{SD})$ & $23.4 \pm 2.8$ & $23.3 \pm 2.9$ & $23.5 \pm 2.6$ & 0.62 \\
\hline $\mathrm{PSA}(\mathrm{mean} \pm \mathrm{SD}): \mathrm{mg} / \mathrm{ml}$ & $11.9 \pm 11.5$ & $12.3 \pm 12.7$ & $11.2 \pm 9.2$ & 0.49 \\
\hline \multirow{2}{*}{$\begin{array}{l}\text { Operation time }(\text { mean } \pm \text { SD) } \\
\text { (median:range) min }\end{array}$} & $174 \pm 50$ & $172 \pm 47$ & $175 \pm 50$ & 0.69 \\
\hline & $170(110-380)$ & $170(115-360)$ & $170(110-380)$ & \\
\hline $\mathrm{EBL}($ mean $\pm \mathrm{SD}): \mathrm{ml}$ & $143 \pm 179$ & $133 \pm 161$ & $149 \pm 188$ & 0.54 \\
\hline Gleason Score & & & & 0.81 \\
\hline 6 & 80 & 52 & 28 & \\
\hline 7 & 91 & 57 & 34 & \\
\hline$\geq 8$ & 44 & 26 & 18 & \\
\hline Pathological stage & & & & 0.45 \\
\hline 2 & 149 & 91 & 58 & \\
\hline$\geq 3$ & 66 & 44 & 22 & \\
\hline Positive surgical margin & & & & 0.1 \\
\hline No & 175 & 105 & 70 & \\
\hline Yes & 40 & 30 & 10 & \\
\hline Prostate volume:g $($ mean $\pm \mathrm{SD})$ & $40.5 \pm 14.8$ & $41.1 \pm 14.7$ & $39.6 \pm 15.1$ & 0.46 \\
\hline MUL, mm $($ mean \pm SD $)$ & $12.7 \pm 3$ & $13.9 \pm 2.8$ & $11.3 \pm 2.8$ & $<0.001$ \\
\hline BNA, degree $($ mean \pm SD) & $105.6 \pm 21.1$ & $109.8 \pm 22.7$ & $98.2 \pm 15.4$ & $<0.001$ \\
\hline Bladder neck position (BNP) & & & & 0.023 \\
\hline BNP-A & 113 & 80 & 34 & \\
\hline BNP-B & 102 & 55 & 46 & \\
\hline
\end{tabular}

BMI: Body mass index; PSA: prostate specific antigen; EBL: estimated blood loss; MUL: membranous urethral length; BNA: Bladder neck angle; BNP-A: BNP above the middle of the pubic symphysis; BNP-B: BNP below the middle of the pubic symphysis.

resulting distribution was compared by log-rank test. Differences were considered statistically significant at $p<0.05$. The Institutional Review Board of our hospital approved this study.

\section{Results}

The clinical and pathological characteristics of 215 patients are shown in Table I. The mean age of patients was 67.5 years (range $=50-76$ years). The median surgical time was 170 min (range $=110-360 \mathrm{~min}$ ), and mean blood loss was 143 $\mathrm{ml}$ (range $=0-800 \mathrm{ml}$ ). Preoperative MRI revealed that mean MUL in 215 patients was $12.7 \pm 3 \mathrm{~mm}$. Mean postoperative bladder neck angle was $105.4 \pm 20.7^{\circ}$. When patients were divided into two groups (continence $(+) v s$. continence $(-)$ ) according to urinary continence 3 month after surgery, MUL (13.9 vs. $11.3 \mathrm{~mm})$, and BNA (109.8 vs. 98.2 $)$ were significantly different (each $p<0.001)$. Using ROC analysis, the optimal cut-off value for preoperative MUL is $12.1 \mathrm{~mm}$ with sensitivity of $68.8 \%$ and specificity of $73.9 \%$ $(\mathrm{AUC}=0.72(95 \% \mathrm{CI}=0.65-0.79))$, and the optimal cut-off value for postoperative BNA is $103^{\circ}$ with sensitivity of $72.3 \%$ and specificity of $58.2 \%(\mathrm{AUC}=0.65(95 \% \mathrm{CI}=0.57-0.72))$
Postoperative cystography was performed successfully in all patients. The leakage of the vesicourethral anastomosis site in cystography was seen in 6 patients $(3 \%)$.

Of the two hundred and fifteen total patients, 135 patients $(62.8 \%)$ achieved an early recovery of UC. In multivariate analysis, MUL (odds ratio $(\mathrm{OR})=5.7 ; p<0.0001)$ and BNA $(\mathrm{OR}=2.4 ; p<0.0001)$ were revealed as independent predictors of early recovery in UC after LRP. In contrast to other reports, our results did not show any significant role of patient age, BMI, and prostate volume in early prediction of the early continence recovery (Table II).

Early recovery rates were $80.3 \%$ in patients with MUL $\geq 12.1 \mathrm{~mm}, 37.5 \%$ in patients with MUL $<12.1 \quad(p<0.001)$, and $77.8 \%$ in patients with $\mathrm{BNA} \geq 103^{\circ}, 50 \%$ in patients with BNA $<103^{\circ}(p<0.001)$. We divided the patients into three groups in accordance with the combination of the two parameters; group A (MUL $\left.\geq 12.1 \mathrm{~mm}+\mathrm{BNA} \geq 103^{\circ}\right)$, group $\mathrm{B}$ (either MUL $<12.1 \mathrm{~mm}+\mathrm{BNA} \geq 103^{\circ}$ or $\mathrm{MUL} \geq 12.1 \mathrm{~mm}+$ BNA $\left.<103^{\circ}\right)$, and group C $\left(\mathrm{MUL}<12.1 \mathrm{~mm}+\mathrm{BNA}<103^{\circ}\right)$. There was no significant demographic difference among the three groups (data not shown). Early recovery rates were $90.4 \%, 58 \%$, and $36.1 \%$ in group A, B and C respectively 
Table II. Univariate and multivariate analysis of factors predicting early continence recovery after LRP.

\begin{tabular}{|c|c|c|}
\hline Variable & $\begin{array}{c}\text { Univariate } \\
p \text {-Value }\end{array}$ & $\begin{array}{c}\text { Multivariate } \\
\text { Odds Ratio }(95 \% \mathrm{CI}) \\
(p \text {-Value })\end{array}$ \\
\hline
\end{tabular}

Age (years)

( $\geq 67$ years $v s .<67$ years) $\quad p=0.77$

BMI $(\geq 24$ vs. $<24) \quad p=0.56$

Operation duration (min)

$(\geq 170$ vs. $<170)$

Bleeding $(\mathrm{ml})$

$(\geq 140$ vs. $<140)$

Prostate volume (g)

$(\geq 40 v s .<40)$

MUL (mm)

$(\geq 12.1$ vs. $<12.1)$

$p=0.32$

$\operatorname{BNA}\left(\geq 103^{\circ} v s .<103^{\circ}\right)$

BNP (upper $v s$. lower)

$$
\begin{aligned}
& p=0.39 \\
& p=0.38
\end{aligned}
$$

$p<0.0001$ $p<0.0001$ $p=0.011$

$$
\begin{gathered}
5.7(3.0-10.8) p<0.0001 \\
2.4(1.1-5.2) p=0.027 \\
1.3(0.6-2.7) p=0.49
\end{gathered}
$$

LRP: Laparoscopic radical prostatectomy; BMI: body mass index; MUL: membranous urethral length; BNA: bladder neck angle; BNP: bladder neck position.

Table III. Comparison of pre- and postoperative parameters in the early continence recovery after $\operatorname{LRP}(n=215)$.

\begin{tabular}{lcc}
\hline & \multicolumn{2}{c}{ Early continence recovery rate $(\%)$} \\
\hline MUL $\geq 12.1(\mathrm{~mm})(\mathrm{n}=127)$ & 80.3 & $p<0.001$ \\
MUL $<12.1(\mathrm{~mm})(\mathrm{n}=88)$ & 37.5 & \\
BNA $\geq 103(\mathrm{n}=99)$ & 77.8 & $p<0.001$ \\
BNA $<103^{\circ}(\mathrm{n}=116)$ & 50 & \\
Group A $(\mathrm{n}=73)$ & 90.4 & \\
Group B $(\mathrm{n}=81)$ & 58 & \\
Group C $(\mathrm{n}=61)$ & 36.1 & \\
\hline
\end{tabular}

MUL: Membranous urethral length; BNA: bladder neck angle; Group A $\left(\mathrm{MUL} \geq 12.5+\mathrm{BNA}>103^{\circ}\right.$ ); Group B (either MUL $<12.1+\mathrm{BNA}>103^{\circ}$ or MUL $\geq 12.1+$ BNA $\left.<103^{\circ}\right)$; Group C $\left(\right.$ MUL $<12.1+$ BNA $\left.<103^{\circ}\right)$.

$(p<0.001)$ (Table III). Kaplan-Meier curves of the time to recovery of UC showed significant differences among the three groups. The mean time to continence recovery was 1 month in group A, 3 months in group B and 4 months in group C (log rank test: $p<0.001)$, (Figure 2).

\section{Discussion}

The etiology of postoperative UI following RP is still unclear, and multiple demographic, and surgical techniquerelated risk factors have been suggested to affect postoperative continence recovery.

Our results that preoperative MUL and postoperative BNA were independent predictive factors for early recovery of UC

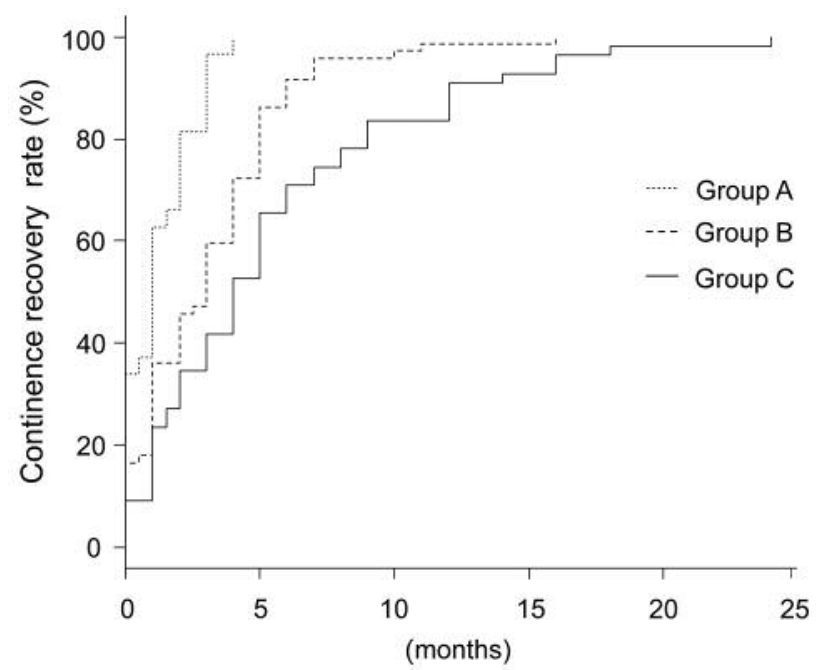

Figure 2. Kaplan-Meier curve of the time to continence in each group divided by the combination of membranous urethral length (MUL) and bladder neck angle (BNA). Group A: $M U L \geq 12.1 \mathrm{~mm}+B N A \geq 103^{\circ}$. Group B: either $M U L \geq 12.1 \mathrm{~mm}$ or $B N A \geq 103^{\circ}$. Group $C: M U L<12.1 \mathrm{~mm}+B N A$ $<103^{\circ}$.

are consistent with previous studies (5.13. 15). On the contrary, age, BMI, and prostate volume were not predictive factors for early recovery of UC in the multivariate analysis. Possible reasons of the results could be the age of the patients in this study was relatively old and range was narrow (mean \pm SD: $67.5 \pm 5.7$ ), and the range of BMI was also relatively narrow (mean \pm SD: $23.4 \pm 2.8$ ).

The membranous urethra contains smooth muscle fibers along its entire length and it is also surrounded by the rhabdosphincter. The combined and coordinated functionality of the intact smooth muscle fibers and the rhabdosphincter has an important role in continence, contributing to maintaining and increasing urethral closure pressures (20-22). Therefore, a longer MUL could result in the increases of the urethral closure pressure followed by early continence recovery.

Postoperative cystography is a useful tool for predicting post-prostatectomy incontinence. A higher vesico-urethral anastomosis location is associated with a higher rate of early recovery of UC, and a wider bladder neck angle is associated with a high rate of early recovery of UC (12-16). Our data also demonstrated that early recovery of UC was observed in patients with wider bladder neck angle, however the postoperative location of bladder neck did not show any significant association with early recover of UC after NNSLRP in multivariate analysis. Thus, BNA could be a more reliable predictor in the finding of cystography. Narrow bladder neck angle might be related to the retraction of membranous urethra into a more distal position in the pelvic cavity by damaging the urethra and surrounding structures during the dissection of apical area of the prostate. 
Therefore, the wider bladder neck angle could be achieved by greater preservation of the urethral sphincter complex in the anatomical and functional position. Furthermore, posterior and anterior reconstruction with urethral suspension might be important surgical procedures to obtain the postoperative longer MUL and wider bladder neck angle.

Fibrosis in the tissue architecture resulted in the dysfunction of multiple organ systems $(23,24)$, and urethra is also shown to be susceptible to fibrotic changes associated with several factors, such as inflammation and aging, which could exert a negative impact on the urethral function, $(25,26)$.

Cartiello et al. (25) have reported that fibrotic changes affecting periurethral prostatic tissue are associated with increased mechanical stiffness and LUTS. Detrusor overactivity arising de novo may be a result of revascularization of the bladder, or inflammatory changes related to RP (27). Inadequate surgical techniques, such as inaccurate vesicourethral anastomosis and injury of urethral sphincter during apical dissection, possibly result in fibrotic tissue development around the urethra. Therefore, surgeons should take care to perform accurate vesicourethral anastomosis and to avoid overdissection of the apical musculature and skeletonizing the urethra. Thus, not only surgical techniques aimed at postprostatectomy incontinence, but also meticulous surgical skill might affect the recovery of UC.

In order to pursue a more reliable predictor of recovery of UC after NNS-LRP, we investigated the continence recovery rates in the combination of MUL and BNA. Continence recovery rates were clearly divided by the combination of MUL and BNA. Early recovery rates in the patients with MLU $\geq 12.1 \mathrm{~mm}+\mathrm{BNA} \geq 103^{\circ}$ were $10.1 \%$ higher than those with MUL $\geq 12.1 \mathrm{~mm}$ alone $(90.4 \%$ vs. $80.3 \%)$. Thus, the combination of longer preoperative MUL and wider postoperative BNA was more reliable predictors of early recovery in UC after NNS-LRP. This information is helpful for patients and physicians to estimate the duration of incontinence which might reduce the patient's anxiety, and consider the application of more aggressive bladder rehabilitation program or further treatments such as male sling or artificial sphincters.

We demonstrated that preoperative MRI and postoperative cystography are useful tools not only for the diagnosis of prostate cancer and the postoperative examination, but also for predicting the period in achieving UC after surgery. However, our study has several limitations. This is a retrospective, single center study with a relatively small number of patients. Furthermore no evaluations by urodynamic studies were performed, although all patients in our study were continent before surgery. Further study may be required to determine whether our findings are applicable to another patient cohort, therefore a prospective multicenter trial is needed to confirm our results.
In conclusion, a combination of preoperative MUL and postoperative BNA was a reliable predictor of recovery of UC after NNS-LRP. Longer MUL with wider BNA is significantly and positively associated with an early recovery of UC after NNS-LRP.

\section{Conflicts of Interest}

All Authors declare that they have no conflict of interest regarding this study.

\section{References}

1 Punnen S, Cowan JE, Chan JM, Carroll PR and Cooperberg MR: Long-term health-related quality of life after primar y treatment for localized prostate cancer: results from the CaPSURE registry. Eur Urol 68: 600-608, 2015.

2 Sanda MG, Dunn RL, Michalski J, Sandler HM, Northouse L, Hembroff L, Lin X, Greenfield TK, Litwin MS, Saigal CS, Mahadevan A, Klein E, Kibel A, Pisters LL, Kuban D, Kaplan I, Wood D, Ciezki J, Shah N and Wei JT: Quality of life and satisfaction with outcome among prostate-cancer survivors. New Engl J Med 358: 1250-1261, 2008.

3 Oefelein MG: Prospective predictors of urinary continence after anatomical radical retropubic prostatectomy: a multivariate analysis. World J Urol 22: 267-271, 2004.

4 Lee SE, Byun SS, Lee HJ, Song SH, Chang IH, Kim YJ, Gill $\mathrm{MC}$ and Hong SK: Impact of variations in prostatic apex shape on early recovery of urinary continence after radical retropubic prostatectomy. Urology 68: 137-141, 2006.

5 Mungovan SF, Sandhu JS, Akin O, Smart NA, Graham PL and Patel MI: Preoperative Membranous Urethral Length Measurement and Continence Recovery Following Radical Prostatectomy: A Systematic Review and Meta-analysis. Eur Urol 71: 368-378, 2017.

6 Van Kapen, De Weerdt W, Van Poppel H, Feys H, Castell Campesino A, Stragier J and Baert L: Prediction of urinary continence following radical prostatectomy. Urol Int 60: 80-84, 1998.

7 Sandhu JS and Eastham JA: Factors predicting early return of continence after radical prostatectomy. Curr Urol Rep 11(3): 191-197, 2010

8 Yamaguchi A, Miyake $H$, Tanaka $K$ and Fujisawa $M$ : Significance of preoperatively observed detrusor overactivity as a predictor of continence status early after robot-assisted radical prostatectomy. Asian J Androl 16: 869-872, 2014.

9 Rocco F, Carmignani L, Acquati P, Gadda F, Dell'Orto P, Rocco B, Bozzini G, Gazzano $G$ and Morabito A: Restoration of posterior aspect of rhabdosphincter shortens continence time after radical retropubic prostatectomy. J Urol 175: 2201-2206, 2006.

10 Nyarangi-Dix JN, Radtke JP, Hadaschik B, Pahernik S and Hohenfellner M: Impact of complete bladder neck preservation on urinary continence, quality of life and surgical margins after radical prostatectomy: a randomized, controlled, single blind trial. J Urol 189: 891-898, 2013.

11 Choi WW, Freire MP, Soukup JR, Yin L, Lipsitz SR, Carvas F, Williams SB and Hu JC: Nerve-sparing technique and urinary control after robot-assisted laparoscopic prostatectomy. World J Urol 29: 21-27, 2011. 
12 Jeong SJ, Yi J, Chung MS, Kim DS, Lee WK, Park H, Yoon CY, Hong SK, Byun SS and Lee SE: Early recovery of urinary continence after radical prostatectomy: correlation with vesicourethral anastomosis location in the pelvic cavity measured by postoperative cystography. Int J Urol 118: 444-451, 2011.

13 Shao IH, Chou CY, Huang CC, Lin CF, Chang YH, Tseng HJ and Wu CT: A Specific Cystography Pattern Can Predict Postprostatectomy Incontinence. Ann Surg Oncol 22(3): S15801586, 2015.

14 Olgin G, Alsyouf M, Han D, Li R, Lightfoot M, Smith D, Nicolay L, Ruckle H and Baldwin DD: Postoperative cystogram findings predict incontinence following robot-assisted radical prostatectomy. J Endourol 28: 1460-1463, 2014.

15 Sugi M, Kinoshita H, Yoshida T, Taguchi H, Mishima T, Yoshida K, Yanishi M, Komai Y, Watanabe and Matuda T: The narrow vesicourethral angle measured on postoperative cystography can predict urinary incontinence after robot-assisted laparoscopic radical prostatectomy. Scand J Urol 52: 151-156, 2018.

16 Kageyama S, Yoshida T, Nagasawa M, Kubota S, Tomita K, Kobayashi K, Murai R, Tsuru T, Hanada E, Johnin K, Narita M and Kawauchi A: The location of the bladder neck in postoperative cystography predicts continence convalescence after radical prostatectomy. BMC Urol 18: 52, 2018.

17 Van Velthoven RF, Ahlering TE, Peltier A, Skarecky DW and Clayman RV: Technique for laparoscopic running urethrovesical anastomosis:the single knot method. Urology 61: 699-702, 2003.

18 Haga N, Ogawa S, Yabe M, Akaihata H, Hata J, Sato Y, Ishibashi K, Hasegawa O, Kikuchi K, Shishido F and Kojima Y: Association between postoperative pelvic anatomic features on magnetic resonance imaging and lower tract urinary symptoms after radical prostatectomy. Urology 84: 642-649, 2014.

19 Kanda Y: Investigation of the freely available easy-to-use software 'EZR' for medical statistics. Bone Marrow Transplant 48: 452-458, 2013.

20 Strasser H, Ninkovic M, Hess M, Bartsch G and Stenzl A: Anatomic and functional studies of the male and female urethral sphincter. World J Urol 18: 324-329, 2000.
21 Strasser H, Pinggera GM, Gozzi C, Horninger W, Mitterberger M, Frauscher F and Bartsch G: Three-dimensional transrectal ultrasound of the male urethral rhabdosphincter. World J Urol 22: 335-338, 2004.

22 Bentzon DN, Graugaard-Jensen C and Borre M: Urethral pressure profile 6 months after radical prostatectomy may be diagnostic of sphincteric incontinence: preliminary data after 12 months' follow-up. Scand J Urol Nephrol 43: 114-118, 2009.

23 Novo E, di Bonzo LV, Cannito S, Colombatto S and Parola M: Hepatic myofibroblasts: a heterogeneous population of multifunctional cells in liver fibrogenesis. Int J Biochem Cell Biol 41: 2089-2093, 2009.

24 Datta A, Scotton CJ and Chambers RC: Novel therapeutic approaches for pulmonary fibrosis. Br J Phamacol 163: 141-172, 2011.

25 Cantiello F, Cicione A, Salonia A, Autorino R, Tucci L, Madeo I and Damiano R: Periurethral fibrosis secondary to prostatic inflammation causing lower urinary tract symptoms: a prospective cohort study. Urology 81: 1018-1023, 2013.

26 Ma J, Gharaee-Kermani M, Kunju L, Hollingsworth JM, Adler J, Arruda EM and Macoska JA: Prostatic fibrosis is associated with lower urinary tract symptoms. J Urol 188: 1375-1381, 2012.

27 Song C, Lee J, Hong JH, Choo MS, Kim CS and Ahn H: Urodynamic interpretation of changing bladder function and voiding pattern after radical prostatectomy: a long-term followup. BJU Int 106: 681-686, 2010. 